
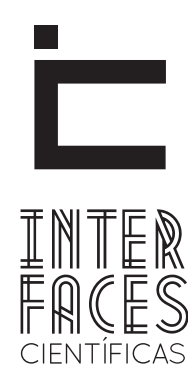

SA ÚDE E AMBIENTE

\title{
A CONSTRUÇ̃̃O DA NOÇÃO DE SUJEITO/DESSUJEITO ENQUANTO FENÔMENO PSICOLÓGICO DENTRO DE UMA HISTORICIDADE E TERRITORIALIZAÇÃO SUBJETIVADA
}

Igor Alexandre Meneses Dantas ${ }^{1}$

\section{RESUMO}

0 presente estudo reflete, de maneira horizontal, as bases históricas e conceituais do sujeito considerado louco, no sentido de dessujeito pelo viés da psicologia contemporânea. Analisa a importância do conceito de alienação mental enquanto formação histórica na sociedade moderna e, com ele, a constituição de um sujeito sujeitado, incapaz de subjetividade e de desejo: um não-sujeito social. Em continuidade, reflete sobre a mudança de vieses que perpassam o dessujeito. Tendo como proposta a construção coletiva do louco, não mais como o indivíduo da não-razão, mas como dessujeitado, isto é, liberto da máquina racional da sociedade.

\section{PALAVRAS-CHAVE}

Loucos. Subjetividade. Psicolocia.

\section{ABSTRACT}

This study reflects a horizontal way, historical and conceptual bases of the subject considered insane in the sense non-subject by the bias of contemporary psychology. Analyzes the importance of the concept of insanity as historical formation in modern society, and with it, the constitution of a subject subjected incapable of subjectivity and desire: a non-social subject. In continuation, reflects on the changing biases that permeate the non-subject. Having proposed as the collective construction of crazy, not as the individual non-reason, but as non-subjected, that is to say, free machine rational society.

\section{KEYWORDS:}

Crazy. Subjectivity. Psychologies. 


\section{RESUMEN}

Este estudio refleja las bases horizontales, históricas y conceptuales de las personas consideradas locas en el sentido despersona de acuerdo con la psicología contemporánea. Analiza la importancia del concepto de locura como la formación histórica de la sociedad moderna, y con ello, la constitución de un sujeto sometido incapaz de subjetividad y el deseo: una no persona social. A continuación, reflexiona sobre los prejuicios cambiantes que impregnan el despersona.
Después de haber propuesto como la construcción colectiva de una locura, no como la no-razón individual, sino como desperonado, es decir, la sociedad racional máquina libre.

\section{PALABRAS CLAVE:}

Loco. La Subjetividad. Psicologías.

\section{INTRODUÇ̃̃̃O}

Em princípio, historicamente, a psicologia moderna submeteu-se às exigências da modernidade na sua ânsia cientificista, dicotomizando aqueles considerados loucos ou sãos, além de desenvolver categorizações que viriam a comprová-los com mais veracidade suas posições no seio da realidade vivida. É através da inserção do universo Psinas dimensões do contemporâneo, que rompemos com a dicotomização, com o compartimentalismo, com o cogito cartesiano, reconhecendo esses indivíduos através da afirmação da diferença.

0 presente artigo tem como objetivo maior, suscitar a mudança dos vieses que permeiam e perpassam esses indivíduos dessujeitados, aprisionando-os, bem como, romper com o silêncio que a psicologia criou em torno dos mesmos.

A partir de um determinado momento histórico, a loucura passa a fazer parte da rede de significações sociais, e, segundo Foucault (2000), o conceito de loucura não existiu sempre, mas inicia sua estruturação em meio à fenda criada entre a razão e a desrazão (que nega a razão como razão)'.

Ao longo do tempo, o conceito de loucura sofreu modificações significativas. Durante o cristianismo,

a loucura era comumente relacionada à possessão, e, consequentemente, à religiosidade. Com as crises econômicas, a loucura e o louco tornam-se sinônimo de irregular, de anormal, de improdutividade. Nossa tentativa não é em conceituar e sim de contextualizar, corroborando com o pensamento de Erasmo de Rotterdam (2003): “Não espereis que, de acordo com o costume dos retóricos vulgares, eu vos dê a minha definição [de loucura] e muito menos a minha divisão" (p. 17). Entendemos que se a definíssemos, estaríamos compartimentalizando-a, favorecendo a sua divisão e não a sua contextualização. “Além disso, por que haveria de me pintar como sombra e imagem numa definição quando estou diante dos vossos olhos e me vedes em pessoa?"॥

Michel Foucault (2000) considerava a loucura herdeira da lepra. Nos dois casos, a exclusão foi adotada como resposta a um "mal" complexo demais para ser solucionado, mas foi necessário um longo período de

I FOUCAULT, Michel. História da loucura na Idade Clássica. São Paulo: Editora Perspectiva, 2000.

II ROTTERDAM, Erasmo de. Elogio da loucura. São Paulo: Editora Martin Claret, 2003. p.17. 
latência, para que a loucura, assim como a lepra, desencadeasse reações de divisão, constituindo um espaço moral de exclusão."I

No final da época medieval, as epidemias e as guerras devastavam o mundo e o tema da morte dominava o pensamento do ocidente. 0 medo e a certeza da finitude humana fazem com que esses tempos sejam assombrados pela presença descarnada da morte. Os hospitais antes ocupados por leprosos são esvaziados, ocorrendo uma mudança de viés no interior dessa inquietude, a figura da loucura substituiu a morte e o fardo que a acompanha. 0 vazio da existência não é mais reconhecido como algo exterior e final, "ele é sentido do interior, como forma contínua e constante da existência"'v.

Iniciado o processo de exclusão da loucura, esta era embarcada na Stultifera Navis - um objeto que domina o imaginário renascentista. A Nau dos Loucos, estranho barco que se move pelos rios e mares, levando consigo sua carga insana de uma cidade para outra. Os loucos eram escorraçados do convívio social, condenados à sina errante. Frequentemente eram deixados sob a responsabilidade de marinheiros, que se incumbiam de levá-los para portos remotos, garantindo assim que não voltariam, tornando-os prisioneiros de sua própria partida.

“Não é fácil levantar o sentido exato desse costume. Seria possível pensar que se trata de uma medida geral de expurgo que as municipalidades fazem incidir sobre os loucos em estado de vagabundagem: hipótese que por si só não dá conta dos fatos, pois certos loucos, antes mesmo que se construam casas especiais para eles, são recebidos nos hospitais e ratados como loucos" (FOUCAULT, 2000, p. 10).

Durante a era clássica nascem os moldes das atuais experiências da loucura. A loucura não é mais figura escatológica, ela é dominada pelos detentores da razão, ou melhor, pelos que a julgam possuir. A Nau dos loucos é "escravizada", esta deixa de exis- tir, no entanto, surge o hospital. O louco "continua a vagar, porém não mais no caminho de uma estranha peregrinação: ele perturba a ordem do espaço social. A loucura, com a pobreza e ociosidade, doravante surge, de modo seco, na dialética imanente dos Estados" (FOUCAULT, 2000, p. 63).

A partir da segunda metade do século XVII, a loucura é sistematicamente internada, aprisionada. Assim como a lepra na Idade Média, o afugentamento se constituiu num mecanismo de segregação social. $O$ internamento do século XVII tem a sua origem na crise econômica que afeta todo o mundo ocidental. Os desocupados, os pobres e os desempregados são sistematicamente aprisionados sob pretexto de garantia da ordem social. Numa sociedade extremamente materialista, voltada para a produção e o lucro, a loucura começa a arraigar-se ao lado da pobreza e da incapacidade para o labor, sendo destituída da liberdade imaginária da renascença, e passando a se instituir em uma problemática socialv.

Antes, livres. Hoje, aprisionados. “Nossa sociedade teme a loucura, rejeita-a e a imagina como um inferno onde não existe qualquer razão [...], a falta de lógica é doença [...], é um caso especial que deve ser levado imediatamente para o hospício" (SERRANO, 1992, P.08).

“Ora, se me excluirdes da sociedade, não só o homem se tornará intolerável ao homem, como também, toda vez que olhar para dentro de si, não poderá deixar de experimentar o desgosto de ser o que é, de se achar aos próprios olhos imundo e disforme, e, por conseguinte, de odiar a si mesmo" (ROTTERDAM, 2003, p. 33).

III Exclusão enquanto efeito intolerável de políticas de desqualificação e estigmatização que ganham consistência em nossa sociedade. SAWAIA, Bader, 2010.

IV FOUCAULT, Michel. História da loucura na Idade Clássica. São Paulo: Editora Perspectiva, 2000. p.16.

V FRAYZE-PEREIRA, João. O que é loucura. São Paulo: Editora Brasiliense, 1982. (Coleção Primeiros Passos: 73 ) 
Delineamos o limite entra a loucura e a normalidade, entre a razão e a desrazão, dessa forma, "descarregamos" e projetamos nos loucos tudo o que tememos dentro de nós, eles são nossos “bodes expiatórios”vI.

Os grandes hospícios e casas de internamento são contemporâneos à era clássica, e assim como ela, já nascem dicotômicos. Obra de assistência e punição, a institucionalização da loucura não é um gesto de aprisionamento apenas, constitui-se num emaranhado de estranhos acoplamentos com significações sócio-políticas, morais, religiosas e econômica, situando-se no contexto das estruturas que regem o mundo clássico (GOFFMAN, 1999, MACEDO e JORGE, 2000).

“O internamento no hospital psiquiátrico separa a razão e a desrazão, tornando a insanidade perceptível dentro da sociedade, não apenas pelo julgamento clínico, mas pelo bom-senso médico que delimita o internar ou libertar [...]. Nesse sentido, a loucura não está voltada para a cura, mas para a exibição do louco, e como uma exaltação da razão para aqueles que permaneciam inseridos na sociedade" (MACEDO e JORGE, 2000, p.130).

Em "A História da Loucura na Idade Clássica" (2000), Foucault não considerava a experiência clássica e moderna da loucura uma figura total, não representando o caminho para a verdade positiva. É uma figura fragmentária, um conjunto desequilibrado por tudo aquilo de que carece, isto é, por tudo aquilo que oculta. Mas apesar disso, a experiência trágica da loucura continuou a persistir em vigília à espera de um desocultamento.

A loucura por muitas vezes encontra-se arraigada ao conceito de desrazão, este faz alusão "à experiência trágica e cósmica da loucura, quando o delírio do louco era entendido como a revelação de uma verdade do mundo"vII. Tal conceito nos remete ao estigma dos indivíduos destituídos de razão, que fogem para além dos limites da mesma, transpondo as normas e regras do pensamento e da linguagem. Façamos agora uma ruptura neste pensamento. Entre a razão e a des-razão, deverá ser compreendido do aporte sujeito e dessujeito. Sujeito é aquele que usa e tem a razão, é o que possui "certeza, lucidez, motivo e causa", variedade de sentidos para o termo razão segundo Marilena Chauí (1995) VIII; o dessujeito é aquele que redimensiona a razão, não pede para tê-la e nem se interessa por ela, que a transforma em des-razão, é o não-sujeito, liberto, livre, o avesso dos "senhores estoicos"|x.

O “louco" (dessujeito) em meio à desordem encontra a liberdade, atuando, portanto, como um subversor da ordem, pois ele age tal qual um nômade, ou seja, "o nômade como desterritorializado por excelência, porque habita a trajetória e se reterritorializa na própria desterritorialização" (DELEUZE \& GUATTARI, apud ALMEIDA \& TRACY, 2003, p. 152).

Imbricados à cartografia da razão e da des-razão, encontram-se os pensamentos acerca da noção de sujeito e a era moderna ou pós-moderna, bem como a psicologia moderna e as psicologias contemporâneas. É na era moderna que o sujeito sujeitado adota "também um papel especificamente moderno, ou

\section{Ibidem}

VII CHAUÍ, Marilena. (1995). Apud FERRAZ, Flávio Carvalho. Andarilhos da imaginação: um estudo sobre os loucos de rua. São Paulo: Casa do Psicólogo. 2000. p.55.

VIII FERRAZ, Flávio Carvalho. Andarilhos da imaginação: um estudo sobre os loucos de rua. São Paulo: Casa do Psicólogo. 2000. p.56.

IX Segundo Erasmo de Rotterdam, o retrato dos senhores estoicos é o seguinte: "Surdo à voz dos sentidos, não sente paixão alguma; o amor e a piedade não impressionam absolutamente o seu coração duro como o diamante; nada lhe escapa, nunca se perde, pois tem uma vista de lince; tudo pesa com a máxima exatidão, nada perdoa; encontra em si mesmo toda a felicidade e se julga o único rico da terra, o único sábio, o único livre, numa palavra, pensa que só ele é tudo, e o mais interessante é que ele é o único a se julgar assim". In: ROTTERDAM, Erasmo de. Elogio da loucura. São Paulo: Editora Martin Claret, 2003. p. 42-43. 
seja, nessa construção, não só os atributos do conceito, mas o próprio sujeito foi se formando e tornando cheio de razão" (MAGER, 2000, p.233). A razão torna-se condição inalienável do sujeito moderno.

Na modernidade, “a desestabilização trabalha no atacado"x. A diversidade e a densificação de universos miscigenados em cada subjetividade acarreta em uma acelerada mutação em torno das figuras e das linguagens, tornando-as obsoletas, fazendo com que surja a necessidade quase que permanente de reconfiguração (ROLNIK, 1996). Tal experiência agregava-se à doença mental, trazendo em seu bojo o medo da não-configuração pactuada com "o mapa absolutizado de uma ordem considerada normal"x।.

\section{PRODUÇ̃̃O SUBJETIVA DE VIDA VERSUS PRODUÇ̃̃̃O SUBJETIVA DE SUJEITO}

Dantas (2003), ao refletir a respeito da construção da noção de sujeito/dessujeito enquanto fenômeno psicológico dentro de uma historicidade e territorialização subjetivada e subjetivante, a partir de entrevistas realizadas com pacientes hospitalizados numa instituição psiquiátrica, definiu categorias interpretativas:

- Produção subjetiva de vida: como os dessujeitados pensam e agem na vida cotidiana;

- Produção subjetiva de sujeito: como os dessujeitados pensam o sujeito.

Tais categorias estão intimamente relacionadas com uma outra categoria de resposta, considerada por Guattari (1999) como sendo de suma importância e significação no modo de perceber a existência humana: a produção de subjetivação.
“Parece-me, contudo, ouvir alguns filósofos dizerem que uma das maiores desgraças para um homem consiste em ficar louco, em viver no erro, na ilusão e na ignorância. Oh! Como estão redondamente enganados! Respondo-lhes, ao contrário, que é justamente nisso que consiste ser homem" (ROTTERDAM, 2003, p.45-46).

Por outro lado, na contemporaneidade, muitas vezes, o sujeito produzido pelos sujeitos capturados foge dessa lógica racional, na sua aspiração de ser livre, na produção de uma outra subjetividade e termina dessujeitando-se como princípio libertador. O sujeito é dimensão dominante produzido por outros sujeitos dominantes. O dessujeito não foi aprisionado por essa lógica e perambula por outras lógicas como nômade.

Os achados demonstram que a percepção da maioria das respostas está dentro da categoria "subjetividade enunciada coletivamente", denotando assim, que pelo fato de serem dessujeitados, alguns pacientes não necessitam de uma referência "sujeito" para se sentirem inclusos socialmente. Outros, entretanto, já precisam dessa referência, sendo a nosso ver oriundos de um processo atual de "normalização", ou seja, à volta ao espaço de homogeneidade territorializado da "sanidade mental": o retorno do sujeito.

X ROLNIK, Suely. Novas figuras do caos: mutações da subjetividade contemporânea. Texto apresentado em mesa redonda no III Congresso Internacional Latino-Americano de Semiótica. PUC-SP, em 04/09/1996. Disponível em: http://www.pucsp.br/nucleodesubjetividade/Textos/SUELY/novascaos.pdf. Acesso em 01 de outubro de 2012.

XI Ibidem. 
"Eu me considero uma pessoa normal, eu me considero que sou uma pessoa normal perante todos, eu sou uma pessoa normal. Eu me fechei agora porque o último acontecimento de ontem me deixou muito chateado, eu queria ver a minha família ontem, eu tava com um aperto no coração, achando que minha família tava lá fora e não deixaram me ver, saíram me arrastando até aí, depois me jogaram que nem um cachorro aí dentro, senti muito chateado, muito chateado mesmo, entendeu? Agora eu sou uma pessoa normal mesmo, não vou fazer mais nada, não vou falar mais nada, não vou fazer nada, vou deixar as coisas acontecerem livremente. Se tiver de acontecer o mais rápido possível seria melhor, né, quanto mais rápido eu sair daqui melhor, quanto mais rápido eu sair daqui melhor as minhas companhias, né". (DANTAS, 2003)

Estes enunciados demonstram que a produção subjetiva de vida também refletida enquanto produção desejante se evidencia nos discursos e na vida cotidiana dos dessujeitos como algo que se precipita ao acaso, nos acontecimentos, no desenrolar dos relevos cartográficos existenciais - tratam-se de acontecimentos, emoções e sentimentos puros, sem passado, presente ou futuro, ou melhor, tudo acontecendo ao mesmo tempo, imanentes, em plena coexistência sem a predeterminação consciente, na atemporalidade.

"No outro dia fui lavar a moto, aí chamei um colega... Quando a gente voltou de manhã, a gente parou em frente a uma lanchonete, de frente ao colégio, lá no João Alves, perto do posto de gasolina. Aí, quando parou lá, tava uma criança abraçada mais o pai; aí, eu disse assim para ele: é seu filho, né? É; e a menina? Também; São gêmeos? São; aí, eu vi a esposa dele chegando, aí, eu disse: oi que coisa bonita, a senhora deveria querer uma menina e ele um menino. Deus foi tão justo com vocês, que colocaram vocês dois, colocaram os dois de uma vez só. Aí, o cara começou a se emocionar, aí, eu vi o impacto das palavras, né, quando eu tava falando; eu olhei assim: não precisa ficar aí se emocionando não, não precisa se emocionar, não precisa se emocionar, a vida de vocês já basta...". (DANTAS, 2003)

Sendo assim, podemos inferir que o modo de dessujeitar a vida pressupõe espíritos livres, libertos de toda moral, razão e assujeitamento, espíritos generosos e doadores de vida e de novos sentidos para esta, que se encontram bem acima das avarentas leis humanas (FUGANTI, 1991). Vidas que não possuem como valores principais a segurança, a regulação, as regras, as leis, os hábitos. Espíritos desprendidos e ousados nos quais reinam as forças ativas e criadoras, isto é, potências artísticas que amam os perigos, as aventuras, o desconhecido, o imprevisível, as misteriosas surpresas do estranho. "Eu prefiro ser essa metamorfose ambulante do que ter aquela velha opinião formada sobre tudo" ${ }^{\prime \prime}$.

\section{CONSIDERAÇ̃̃ES FINAIS}

0 presente estudo refletiu, de maneira bastante horizontal, as bases históricas e conceituais do sujeito/dessujeito pelo viés da psicologia contemporânea. Analisou a importância do conceito de alienação mental enquanto formação histórica na sociedade moderna e, com ele, a constituição de um sujeito sujeitado, incapaz de subjetividade e de desejo: um não-sujeito social. Em continuidade, refletimos sobre a mudança de vieses que perpassam o dessujeito. Tendo como proposta a construção coletiva do "louco", não mais

XII SEIXAS, Raul. Metamorfose Ambulante. In: KRIG-HA, BANDOLO!. Produzido por Philips/Phonogram, São Paulo: Phonogram, [1973]. 1 CD (47min.) Faixa 2 (3min. 45s.). 
como o indivíduo da não-razão, mas como dessujeitado, isto é, liberto da máquina racional da sociedade.

Concernente à produção subjetiva de sujeito, evidenciamos que a grande aliança proposta pelo pensamento psicológico contemporâneo conjura todo o corte, toda a hierarquia e a eminência da alma sobre o corpo e estabelece uma relação recíproca duplamente positiva. Por um lado, a vida ativando o pensamento, por outro lado o pensamento afirmando a vida. Ora o passo de um, ora o passo da outra. Ora um lance da vida, ora um lance do pensamento. Ora a vida ultrapassando os limites do pensamento, ora o pensamento ultrapassando os limites da vida. Ora os encontros ou misturas de corpos desterritorializando as maneiras de pensar, ora os atos afirmativos de pensamento desterritorializando os modos de agir. Jogo alegre, ativo e afirmativo do tempo, que acontece no seio da diferença dos corpos, distância necessária à liberdade ativa dos devires e afirmada pela potência autônoma do pensamento. Jogo leve e alegre da dança dos fluxos nômades que acontece no campo do acaso, longe, à boa distância da segurança das fixações sedentárias da razão negativa e das vidas reativas.

Os ditos "loucos", os dessujeitos por excelência, observam os supostos detentores da razão de uma maneira própria, de uma maneira singular, única e exclusivamente não-sujeitada. Percebem-nos enquanto "escravos" da máquina capitalista e moderna, aprisionados em nosso próprio mundo lógico e racional, correto e pré-moldado, compartimentalizado e sujeitado. Evidenciando-nos uma realidade a qual nos negamos acreditar e aceitar.

\section{REFERÊNCIAS}

DANTAS, Igor Alexandre Meneses, Dizem que sou louco por pensar assim: entre a razão e a des-razão, orientação [de] Alberto Pereira Garcia. Aracaju, 2003.

DELEUZE, Gilles \& GUATTARI, Félix. Apud ALMEIDA, Maria Isabel Mendes de; TRACY, Kátia Maria de Almeida. Noites nômades: espaço e subjetividade nas culturas jovens contemporâneas. São Paulo: Rocco, 2003. p.152.

FERRAZ, Flávio Carvalho. Andarilhos da imaginação: um estudo sobre os loucos de rua. São Paulo: Casa do Psicólogo, 2000.

FOUCAULT, Michel. Doença mental e Psicologia. 5. ed. Rio de Janeiro: Tempo Brasileiro. 1994.

FOUCAULT, Michel. História da loucura na Idade Clássica. 6. ed. São Paulo: Perspectiva, 2000.

FRAYZE-PEREIRA, João. 0 que é loucura. São Paulo: Brasiliense, 1982. (Coleção Primeiros Passos: 73 ).

FUGANTI, Luiz Antônio. Saúde, desejo e pensamento. In: LANCETTI, Antônio (Org.). SaúdeLoucura 2. 3. ed. São Paulo: Hucitec, 1991. pp. 19-82.

GUATARRI, Félix; ROLNIK, Suely. Micropolítica: cartografias do desejo. 5. ed. Petrópolis: Vozes, 1999. 
GOFFMAN, Erving. Manicômios, prisões e conventos. 6. ed. São Paulo: Perspectiva. 1999.

LAKATOS, Eva Maria \& MARCONI, Marina de Andrade. Fundamentos de Metodologia Científica - 4. ed. São Paulo: Atlas, 2001.

MACEDO, Adriana Maria Bento \& JORGE, Maria Salete Bessa. Concepções de loucura e sua influência na pratica psiquiátrica. In: JORGE, Maria Salete Bessa, SILVA, Waldine Viana da \& OLIVEIRA, Francisca Bezerra de. (Org.). Saúde mental: da prática asilar ao terceiro milênio. São Paulo: Lemos Editorial, 2000. p. 125-148.

MAGER, Miryan. Preliminares para um debate: do sujeito sujeitado para um sujeito dessujeitado. PSI - Revista do Departamento de Psicologia Social e Institucional, Londrina, vol. 2, n. 2, pp. 231-250, dez. de 2000.

ROLNIK, Suely. Novas figuras do caos: mutações da subjetividade contemporânea. Texto apresentado em mesa redonda no III Congresso Internacional Latino-Americano de Semiótica. PUC-SP, em 04/09/1996. Disponível em: htttp://pucsp.br/nucleodesubjetividade/Textos/SUELY/novascaos.pdf. Acesso em 01 de outubro de 2012.

ROLNIK, Suely. Psicologia: subjetividade, ética e cultura. In: LANCETTI, Antônio (Org.). SáudeLoucura 6. Subjetividade: questões contemporâneas. 2. ed. São Paulo: Hucitec, 1997. pp. 13-21.

ROTTERDAM, Erasmo de. Elogio da loucura. São Paulo: Martin Claret, 2003. (Série Ouro: 37).

SAWAIA, BADER (Org.). [et. al.] As artimanhas da exclusão: análise psicossocial e ética da desigualdade social. 10 ed. Petrópolis, RJ: Vozes, 2010.

SEIXAS, Raul. Metamorfose Ambulante. In: KRIG-HA, BANDOLO!. Produzido por Philips/Phonogram, São Paulo: Phonogram, [1973]. 1 CD (47min.) Faixa 2 (3min. 45s.)

SERRANO, Alan Índio. 0 que é psiquiatria alternativa. 7. ed. São Paulo: Brasiliense, 1992. (Coleção Primeiros Passos: 52 ) 